\title{
FOLLOW THE CURRENT OF MORPHOLOGICAL DEVELOPMENT AND STATE OF STUDENTS PARTICIPATING IN „SNOW SPORTS” COURSE
}

\author{
Milena Zdravcheva, Krastyo Zgurovski, Dimitar Pavlov \\ National Sports Academy „Vassil Levski”, Sofia, Bulgaria
}

\begin{abstract}
Conducting a Snow Sports course takes place in the high part of the mountain (about 2000 meters above sea level), far from the known and usual locations and training, which makes the training conditions run in unusual conditions. These conditions provoke the development of a stress state as a state of increased tension of all functions of the body and psyche. Physical environmental factors are defined as non-standard conditions.

Using the anthropometry method, we will monitor the dynamics of the variables affected by the load in the course
\end{abstract}

Key words: anthropometry, somatotype morphological status, training course, snow sports

\section{INTRODUCTION}

Dr. Sheldon defines the somatotype as genetically determined, not subject to change, but according to two other scientists, however, Lindsay Carter, a professor of physical education at the University of San Diego and Barbara Heath, an anthropologist at the University of Pennsylvania, the somatotype changes under the influence training, nutrition, growth and aging of the body. Somatotype is a qualitative description of the present shape and composition of the human body. It can be used to record changes in physics and to assess biological differences and similarities between people. The somatotype method is sensitive to physique changes over time and is used to rank both sexes at all ages.

The density of the program requires the maximum mobilization of the will and physical qualities of a person for everyday high loads. Classes are held 3 hours before noon and 3 hours after noon, with students having an hour and a half rest. The workplaces are reached by climbing devices (trains), but during the first days of the course, before they have mastered the speed control skills, students move without trains. These days also coincide with their adaptation given the high altitude (about 2000m). The meteorological situation in the high and open mountains, which in many cases is unfavorable, combined with the heavy equipment of about $8 \mathrm{~kg}$, puts to the test their mental and physical qualities. It is in this connection that we have chosen the method of anthropometry, with which to trace the dynamics of the variables, which are influenced by the load in the course. Preliminary studies in this regard relate to anthropometric features that are morphological, somatometric (height and other body lengths, pectoral and other circumferences, diameters, etc.) and functional, physiometric (vital capacity, muscular strength, flexibility and joint mobility), contractile and respiratory difference, skin folds, etc. (Toteva, 1992).

Our hypothesis is based on the somatotype, which is an integral assessment of the shape and structure of the human body. Its use as an evaluation criterion has long been proven in sports practice. (Toteva, 1992).

For a more comprehensive characterization of the morphological status of students, we use the somatotype determination methodology. In the 1940s, the English scientist Dr. William Sheldon classified 3 major body types. He calls them somatotypes ectomorphs, mesomorphs, and endomorphs.

In this regard, we looked at the somatotype types on which we based the data obtained: Endomorphic somatotype, Mesomorphic somatotype, Ectomorphic somatotype - (Slunchev, 1998)

The three estimates are given sequentially endomorph-mesomorph-ectomorph (3.00-4.00-5.00). Thirteen major somatotypes are characterized.

Purpose: Measurement and diagnosis of the physical development of students participating in the Snow Sports course at the beginning and end of the course. 
Tasks:

1. To determine the somatotypological indicators relevant to the purpose of the study.

2. Define BMI at the beginning and end of each long shift for both sexes.

3. Compare the survey data.

4. To track the dynamics of the morphological development of the students participating in the course.

\section{METHODOLOGY}

Research Methods:

$\checkmark$ Calyperometry and measurement of anthropometric indicators of 134 students (62 women and 72 men) participating in the Snow Sports course, at the beginning and end of the course.

$\checkmark$ Mathematical - statistical methods, comparative analysis.

Organization of the study: To determine the somatotype of students participating in Snow Sports courses using a caliper, standard medical weight meter and centimeter tape, we measured the following characteristics at the beginning and end of the course: height; weight; a skin fold at the lower corner of a scapula; triceps skin fold; skin fold on inner side of thigh: skin fold on upper thigh; armpit circumference; tour of the forearm; lap thigh; lap tour; biopicondylar diameter of the shoulder bone; femoral diameter of the femur.

Based on the data body length and body weight we calculated the BMI body mass index according to the formula $\mathbf{B M I}=\frac{W}{h^{2}}$, where: $\mathrm{W}$ - weight in kilograms; $h$ height in meters. The index score is determined by a table compiled by the World Health Organization.

We entered the data into an excel table and, us- ing the appropriate formulas, determined the type of somatotype.

\section{RESULTS AND DISCUSSION}

Using the methodology described, we have identified the somatotypic characteristics of students in the Snow Sports course. Table 1 presents the statistical values. In women, we identify the following components at the beginning of each shift (2.39 3.46 - 2.74). This combination shows a central somatotype. The three components do not differ by more than one unit and have values from 2 to 4 .

Women have specific anthropometric indicators compared to men: women's height and weight are smaller. The carcass in women is longer than in men, the lower and upper limbs are shorter, the shoulders are narrower, the pelvis is wider. It is characterized by a more rounded shape of the female body at the expense of significantly less development of skeletal muscle and a thicker layer of subcutaneous fat, reaching up to $28 \%$ of their body weight in women, against $12-18 \%$ in men. (Gavriiski, et al, 2006). Despite the above-mentioned morphological features, there are wide individual variations in the structure of the female body.

From the data, it is clear that the female students are: low to high in height, with athletic structure and a moderate percentage of subcutaneous fat, revealing the back, chest muscles, muscles in the hands and to some extent the muscles in the hips. Usually, the problematic fat is in the abdomen and thighs, along with greater buttock muscles. From this somatotype, steps are possible in the direction of almost all types of sports, depending on the person's height and weight. The information presented above is a prerequisite for many women to cope with mastering the ski technique without difficulty.

Table 1. Statistical values characterizing students' physical development

\begin{tabular}{|c|c|c|c|c|c|c|c|c|c|}
\hline \multirow[b]{2}{*}{ gender } & \multicolumn{2}{|c|}{ Height } & \multicolumn{2}{|c|}{ Weight } & \multicolumn{2}{|c|}{ BMI } & \multirow{2}{*}{ Endomorphic } & \multirow{2}{*}{ Mesomorphic } & \multirow{2}{*}{ Ectomorphic } \\
\hline & Av & Sav & Av & Sav & Av & Sav & & & \\
\hline Women $\mathrm{n}$ & 165,81 & $\underline{6,13}$ & $\underline{59,46}$ & $\underline{9,85}$ & 21,59 & $\underline{3,14}$ & 2,39 & $\underline{3,46}$ & 2,74 \\
\hline$=62$ & 165,81 & 6,13 & 58,24 & 9,39 & 21,15 & $\underline{2,97}$ & 2,00 & 3,35 & 2,75 \\
\hline $\begin{array}{c}\text { Men } \\
\mathrm{n}=\mathbf{7 2}\end{array}$ & $\frac{179,58}{179,58}$ & $\frac{7,12}{7,12}$ & $\frac{75,15}{73,88}$ & $\frac{9,24}{8,87}$ & $\frac{23,31}{22,92}$ & $\frac{2,64}{2,58}$ & $\frac{1,27}{0,94}$ & $\frac{4,83}{4,71}$ & $\frac{2,69}{2,69}$ \\
\hline
\end{tabular}

Note: the numerators represent the data at the beginning of the course and in the denominator the data from the measurement at the end of the course.

The characteristic of the distribution of variables for endo, meso and ecto somatotype is presented 


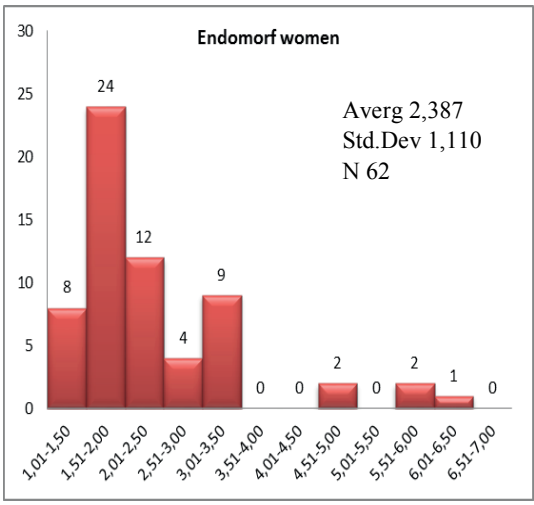

Figure 1. Endomorf women

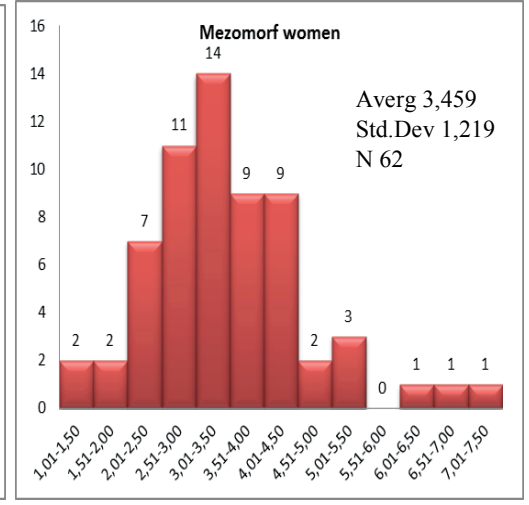

Figure 2. Mezomorf women

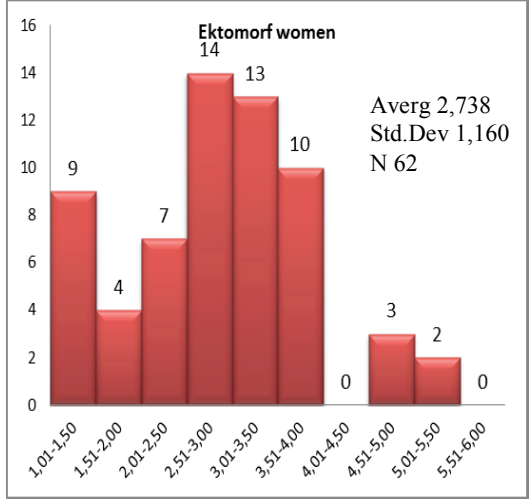

Figure 3. Ektomorf women
An endomorphic distribution histogram shows a set of units in the range of 1.00 to 2.50 . It is averaged 2,387 and a standard deviation of 1,110 . In the mesomorphic histogram there is a normal distribution of units, the standard deviation is 1.219. Units in the ectomophilia histogram can also be considered as normal with poorly expressed right asymmetry.

At the end of the course data were reported (2.00 3.35 - 2.75). The endomorphic index was lowered by 0.39 , which indicates a reduction in subcutaneous fat.

In men, we find average components (1.27 - 4.83 - 2.69) (Table 1). This combination reveals an ectomorphic mesomorph - mesomorphism is highest and ectomorphism is higher than endomorphism. Ecto-mesomorphs are mostly ectomorphs, with some features of mesomorphs. In general, they are of high structure and more muscle mass than true ectomorphs, but still less than true mesomorphs or meso-ectomorphs.

Typical features: small volume and structure of bones, ability to build more muscle, flat as vision mus- cles, medium shoulder width, relatively fast metabolism.

The distribution characteristics of the variables for endo, meso and ecto somatotype are presented graphically in the histograms (Figures 4,5 and 6).

Figure 4 shows the endomorphism, which has a mean of 1.27 and a standard deviation of 0.95 . A low value determines a small amount of subcutaneous fat. The distribution is normal for the already determined somatotype type. The histogram shows that at its highest, 52 students from the sample surveyed, which is $72.22 \%$ of all men studied.

The mesomorphy distribution (Figure 5) is statistically characterized by a mean of 4.83 and a standard deviation of 1.22. The histogram has a symmetrical, normal distribution with a slight increase in the left, but generally the units are concentrated near the center.

Ectomorphs (Figure 6) are determined by an average of 2.69 and a standard deviation of 1.20. A low value determines a small linearity of the body and a large amount of relative mass at a certain height.

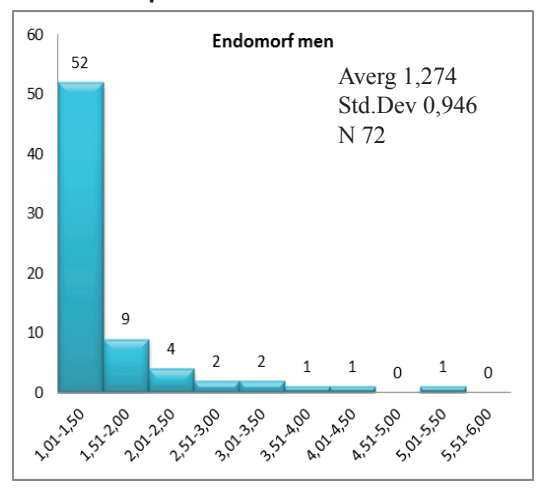

Figure 4. Endomorf men

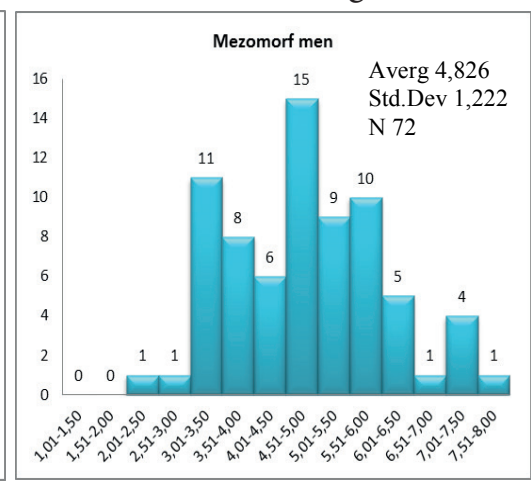

Figure 5. Mezomorf men

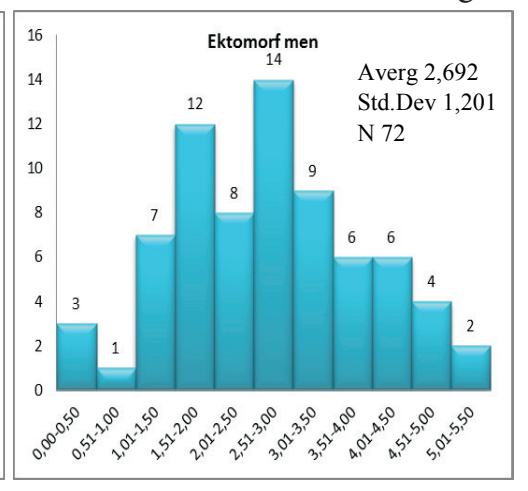

Figure 6. Ektomorf men

The characteristics of the somatotype indicators morphic one by 0.12 .

at the end of the course in men are respectively One of our tasks is to analyze the body mass in$(0.94-4.71-2.69)$. Also, as in women, the endo- dex as a derivative of body length and weight. To morphic index is decreased -0.33 , and the meso- analyze the data, we used a table approved by the 
World Health Organization in 1995.

In the methodological plan of the study, we planned to monitor the dynamics of the BMI, taking into account that it correlates significantly with the somatotype of the athletes, especially with their functional state, which is examined using the Rufier test. An example of such interaction is the ALPHA-FIT Test
Battery Carolina University, Denmark 2009.

Table 2 lists the statistics for women. At the beginning of the study, BMI averaged 21.59 with a standard deviation of 3.14. According to the $\mathrm{WHO}$ table, these values are estimated as normal body weight. At the end of the course, the mean was 21.15 and a standard deviation of 2.97 .

Table 2. Physical development women

\begin{tabular}{|c|c|c|c|c|c|c|c|c|}
\hline \multirow{2}{*}{ № } & \multirow{2}{*}{ Indicator } & \multirow{2}{*}{$\mathbf{n}$} & \multicolumn{6}{|c|}{ Statistical characteristics } \\
\hline & & & $\mathrm{X} \min$ & $X \max$ & $\mathbf{R}$ & Av & Sav & V\% \\
\hline 1. & height & 62 & 150 & 179 & 29 & 165,81 & 6,13 & 3,70 \\
\hline 2. & Weight at the beginning & 62 & 43 & 88 & 45 & 59,46 & 9,85 & 16,57 \\
\hline 3. & Weight at the end & 62 & 42 & 85 & 43 & 58,24 & 9,39 & 16,12 \\
\hline 4. & BMI in the beginning & 62 & 17,24 & 32,72 & 15,46 & 21,59 & 3,14 & 14,55 \\
\hline 5. & BMI at the end & 62 & 16,90 & 31,60 & 14,71 & 21,15 & 2,97 & 14,06 \\
\hline
\end{tabular}

Note: $X$ min - minimum value; $X$ max - maximum value;

$R$ is the range (interval). difference between maximum and minimum value; Av-arithmetic mean;

Sav - standard deviation; V\% - coefficient of variability

The coefficient of variability at the beginning was $14.55 \%$ and at the end $14.06 \%$, indicating that the sample was approximately homogeneous. The his-

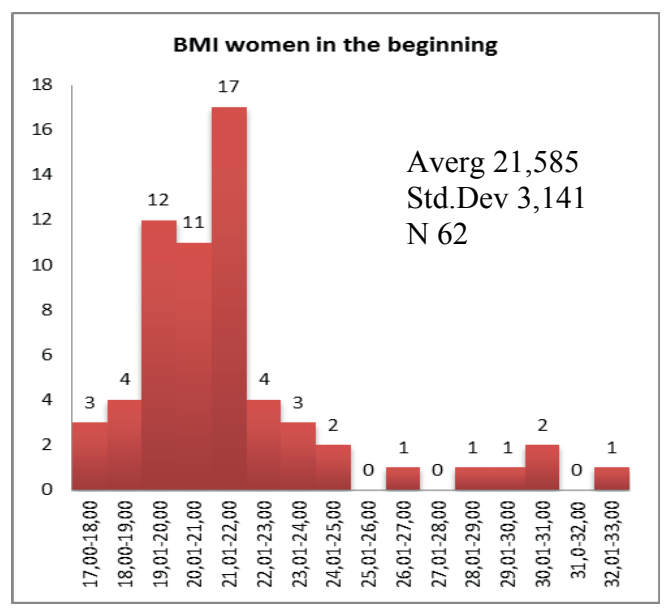

Figure 7. BMI women in the beginning

Both histograms have considerable symmetry on the right. The analysis of the data shows that many female students have lowered their body mass index, but overall the average distribution is almost the same, with a minimal decrease as with the analyzed data from the beginning of the course (Table 3). tograms of Figure 7 and Figure 8 give a more detailed picture of the variables.

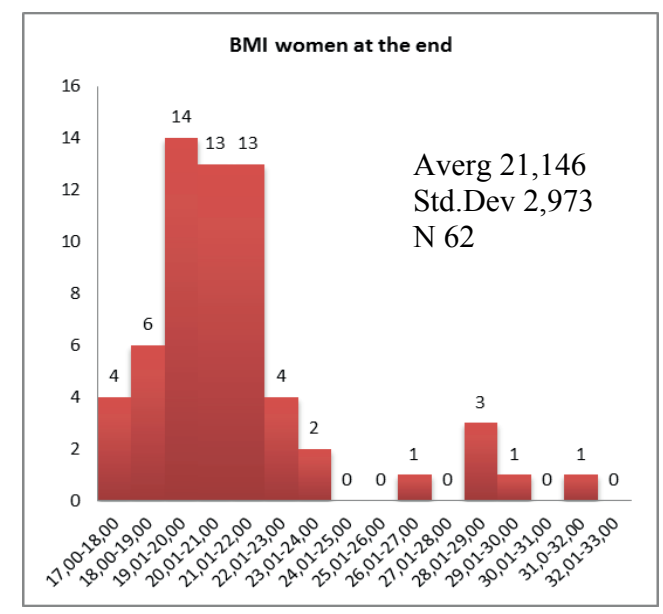

Figure 8. BMI women at the and

Table 3 shows the quantitative statistics on BMI in men and the graphical histograms in Figures 9 and 10. According to WHO estimates (Table 1), men should also be included in the normal body weight column. 
Table 3. Physical development men

\begin{tabular}{|c|c|c|c|c|c|c|c|c|}
\hline \multirow{2}{*}{ № } & \multirow{2}{*}{ Indicator } & \multirow{2}{*}{$\mathbf{n}$} & \multicolumn{6}{|c|}{ Statistical characteristics } \\
\hline & & & $\mathrm{X} \min$ & $\mathrm{X} \max$ & $\mathbf{R}$ & $\mathbf{A v}$ & Sav & $\mathrm{V} \%$ \\
\hline 1. & Height & 72 & 162 & 200 & 38 & 179,58 & 7,12 & 3,96 \\
\hline 2. & Weight at the beginning & 72 & 60 & 97 & 37 & 75,15 & 9,24 & 12,30 \\
\hline 3. & Weight at the end & 72 & 58 & 94 & 36 & 73,88 & 8,87 & 12.01 \\
\hline 4. & BMI in the beginning & 72 & 18,11 & 32,69 & 14,58 & 23,31 & 2,64 & 11,33 \\
\hline 5. & BMI at the end & 72 & 18,42 & 31,96 & 13,54 & 22,92 & 2,58 & 11,27 \\
\hline
\end{tabular}

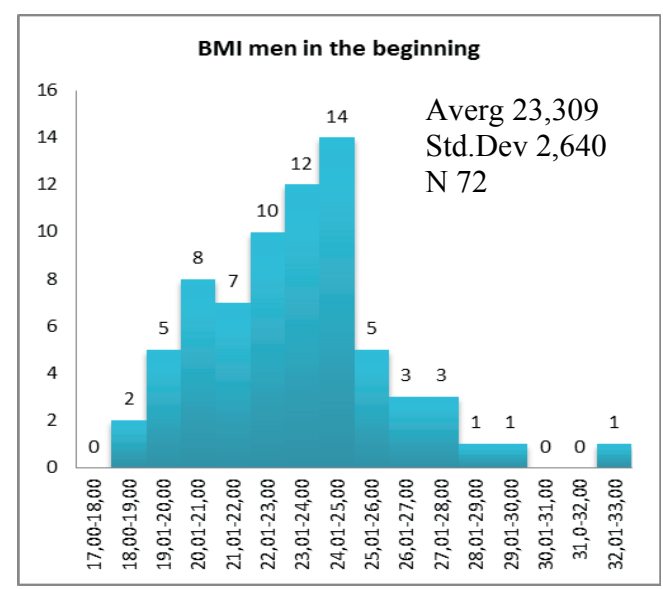

Figure 9. BMI men in the beginning

The comparative analysis of BMI values in men is similar to the results in women. Also, many students have reduced their body mass index. The average BMI in the first study was 23.31 , and at the end of the course - 22.92, the decrease was $1.71 \%$ or 0.39 .

\section{CONCLUSION}

The changes in the variables of endo, meso and ecto somatotype occurring within 14 days are insignificant, which confirms the theoretical foundations of the somatotype method for such a period of time, regardless of the specifics of the Snow Sports training course. However, a change was observed in the ecto component of both sexes for women by 0.39 and for men by 0.33 . Although there is a change in BMI indicators, it should be noted that it is also insignificant for the training period. In women, BMI decreased by 0.44 and in men by 0.39 .

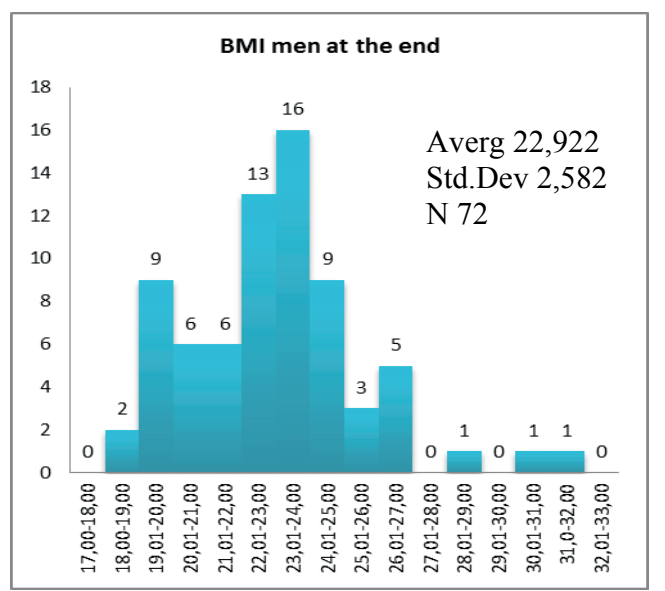

Figure 10. BMI men at the end

\section{REFERENCES}

Gavriiski, V., Stefanov, D., Kiselnova, E., Bichev, K. (1998). Fiziologiya na choveka s fiziologiya na sporta chast II., Novi znaniya. Sofia

Gavriüski, V., Stefanova, D., Kiselnova, E., Bichev, K. (2006). Fiziologiya na choveka s fiziologiya na sportachast III., Novi znaniya. Sofia

Slunchev, P. (1990). Sportna meditsina., Novi znaniya. Sofia

Toteva, M. (1992). Somatotipologiya v sporta. "NSA Pres" Sofia.

Flăshman, E. (1970). Struktura i izmervane na fizicheskata godnost. Durzhavno voenno izdatelstvo. Sofia

Carter, J.E.L., Heath, B. H. (1990). Somatotyping - development and applications, Cambridge University Press, Cambridge

\section{Corresponding author:} MilenaZdravcheva

National SportsAcademy „Vassil Levski”, 21Akad. Stefan Mladenov str. Sofia 1700, Bulgaria

E-mail: milenazdravcheva@gmail.com 